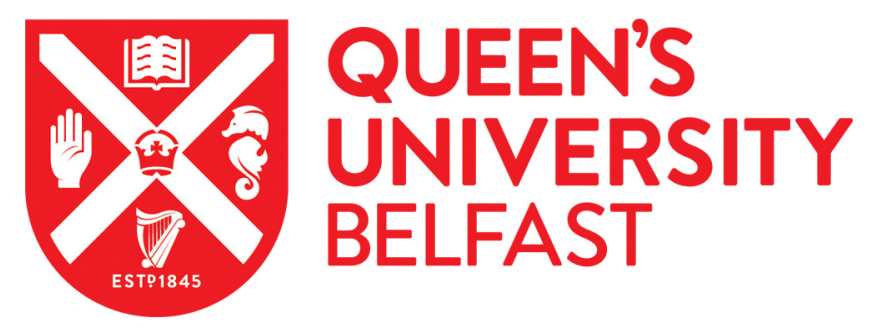

\title{
User perspective on palliative care services: experiences of middle- aged partners bereaved through cancer known to social work services in Northern Ireland
}

Roulston, A., Manktelow, R., \& Donaghy, K. (2008). User perspective on palliative care services: experiences of middle-aged partners bereaved through cancer known to social work services in Northern Ireland. Practice, 20 (3)(3), 163-180. https://doi.org/10.1080/09503150802341400

Published in:

Practice

Queen's University Belfast - Research Portal:

Link to publication record in Queen's University Belfast Research Portal

\section{General rights}

Copyright for the publications made accessible via the Queen's University Belfast Research Portal is retained by the author(s) and / or other copyright owners and it is a condition of accessing these publications that users recognise and abide by the legal requirements associated with these rights.

Take down policy

The Research Portal is Queen's institutional repository that provides access to Queen's research output. Every effort has been made to ensure that content in the Research Portal does not infringe any person's rights, or applicable UK laws. If you discover content in the Research Portal that you believe breaches copyright or violates any law, please contact openaccess@qub.ac.uk. 
This article was downloaded by: [Agnew, Audrey]

On: 2 September 2008

Access details: Access Details: [subscription number 902104684]

Publisher Routledge

Informa Ltd Registered in England and Wales Registered Number: 1072954 Registered office: Mortimer House, 37-41 Mortimer Street, London W1T 3JH, UK

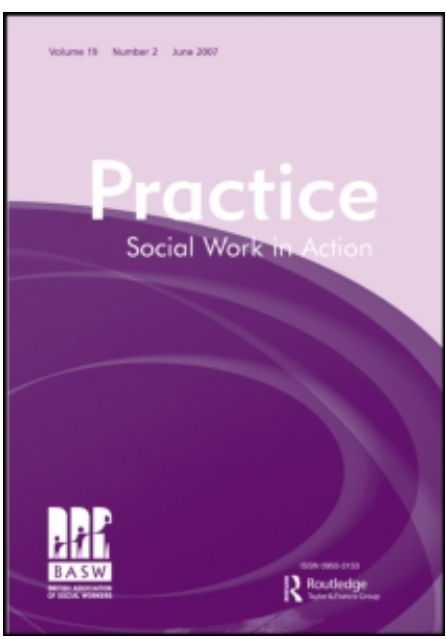

\section{Practice}

Publication details, including instructions for authors and subscription information:

http://www.informaworld.com/smpp/title content=t713665951

\section{User Perspective on Palliative Care Services: Experiences of Middle-aged Partners Bereaved through Cancer Known to Social Work Services in Northern Ireland \\ Audrey Agnew; Roger Manktelow; Kevin Donaghy}

Online Publication Date: 01 September 2008

To cite this Article Agnew, Audrey, Manktelow, Roger and Donaghy, Kevin(2008)'User Perspective on Palliative Care Services: Experiences of Middle-aged Partners Bereaved through Cancer Known to Social Work Services in Northern Ireland',Practice,20:3,163 $-180$

To link to this Article: DOI: $10.1080 / 09503150802341400$

URL: http://dx.doi.org/10.1080/09503150802341400

PLEASE SCROLL DOWN FOR ARTICLE

Full terms and conditions of use: http://www.informaworld.com/terms-and-conditions-of-access.pdf

This article may be used for research, teaching and private study purposes. Any substantial or systematic reproduction, re-distribution, re-selling, loan or sub-licensing, systematic supply or distribution in any form to anyone is expressly forbidden.

The publisher does not give any warranty express or implied or make any representation that the contents will be complete or accurate or up to date. The accuracy of any instructions, formulae and drug doses should be independently verified with primary sources. The publisher shall not be liable for any loss, actions, claims, proceedings, demand or costs or damages whatsoever or howsoever caused arising directly or indirectly in connection with or arising out of the use of this material. 


\title{
User Perspective on Palliative Care Services: Experiences of Middle-aged Partners Bereaved through Cancer Known to Social Work Services in Northern Ireland
}

\author{
Audrey Agnew, Roger Manktelow \\ and Kevin Donaghy
}

\begin{abstract}
This qualitative research study explores experiences of partners bereaved through cancer, who were resident in an urban area of Northern Ireland and who had been service users of the social work services. Data were collected in 2004 from 10 individuals who participated in semi-structured interviews. Emergent themes were identified using thematic content analysis and findings analysed under four categories: cancer journey; impact of bereavement; process of adjustment and change; and experience of support services. Opportunities to facilitate communication were not always maximised, often resulting in poor bereavement outcomes. Although hospices undertook bereavement risk assessment, participants were unaware of its use and queried its accuracy without service user involvement. The most cited informal support was family and friends, although such help was time-limited. Service user feedback regarding social workers was generally positive; however, there was a lack of knowledge about their role in palliative care. Post-bereavement adjustment was influenced by the quality of social networks, the responsibilities of lone parenthood, and challenges to life values and core beliefs. A framework for palliative care social work has been recommended based on research findings.
\end{abstract}

Keywords: bereavement; social work; palliative care

\section{Introduction}

Although research in palliative care is increasing, there is insufficient evidence to enable us to support patients' families appropriately both pre- and postbereavement (Addington-Hall 2007). This challenges us in the areas of 
accountability, research promotion, evidence-based practice and service user evaluation against the demands of increased cost-effectiveness within the Health Service.

Grief is a shared human experience, which, whilst influenced by common external factors, remains unique to each individual (Kissane et al. 1997; Benight et al. 2001). Close family bereavement is recognised as one of the most stressful experiences we face in our lifetime (Archer 1999; Ringdal et al. 2001) and death of a partner causes even more severe and protracted grief than other bereavements (Parkes 2006). Furthermore, cancer continues to be universally feared because of its insidious onset, its indiscriminate nature and the absence of an effective cure (Purandare 1997; Parkes 2006; Beresford et al. 2007). In Northern Ireland there were 3639 cancer-related deaths in 2005 (www.qub.ac. uk/researchcentres/nicr).

There are many points throughout the disease trajectory where relatives experience anticipatory grief. These can provide opportunities for professionals to facilitate communication between patients and families to help realise the inevitability of death, resolve unfinished business and consider how to deal with future issues (Worden 1991). Preparedness for an impending death is known to help minimise the risk of poor bereavement outcome (Barry et al. 2002; CFAH 2003), although this may not always be welcomed or facilitated.

A number of bereavement models have previously been proposed (Freud 1917; Lindemann 1944; Bowlby 1969; Kubler-Ross 1969; Parkes 1986; Worden 1991) but more recently have been superseded (Valentine 2006) by modern theorists (Stroebe et al. 2006; Machin and Spall 2004) who have developed frameworks based on the Dual Process Model (Stroebe and Schut 1999) and the Range of Response to Loss (Machin 2001). Here grieving is seen as oscillation between lossoriented and restoration-oriented coping, which is influenced by numerous life characteristics (Stroebe and Schut 1999). The strength of this approach is that it recognises individuality and the importance of service user involvement to prevent inaccurate outcomes. Bereavement is a multi-dimensional process which affects individuals mentally, physically, socially, financially and spiritually, which may take a bereaved individual many years to adjust to, if ever (Arbuckle and de Vries 1995; Osterweiss et al. 1984).

A continuous holistic assessment conducted by a qualified practitioner equipped with a comprehensive understanding of grief is necessary (Benight et al. 2001; Scannell-Desch 2003) to inform the type and degree of postbereavement support required (Stroebe and Schut 2001; Chrystal-Frances 2003; NICE 2004; Parkes 2006). Professionals can only prioritise bereavement follow up if such a formalised assessment is conducted; at present this is approached inconsistently (Reid et al. 2006) and it remains unclear who should undertake this role. Bereaved people regard this as the GP's role (Lloyd-Williams 1995; Main 2000); however, it is suggested that only GPs who have a special interest in palliative care offer routine bereavement support (Harris and Kendrick 1998). Although nurses play a vital role in supporting patients and families prebereavement, they query their involvement post-bereavement due to a lack of 
resources and require training to assess grief reactions (Birtwistle 2004). Despite the widespread lack of service user knowledge about what social workers do, they value social work as an essential part of palliative care provision (Beresford et al. 2007).

Service user feedback is recognised as key to service planning, delivery and review. Bereaved caregivers provide insight into the provision of care at the end of life (Beaver et al. 1999; Exley and Tyrer 2005) and their experiences of bereavement follow-up support. Firth et al. (2005) highlight the diversity in availability of services. With this in mind, this research was undertaken with bereaved service users.

\section{Methodology}

The aim of the research was to retrospectively explore certain pre- and postbereavement experiences of partners bereaved through cancer. Investigation centred on the impact of bereavement and on the service user's experiences of bereavement support from both informal and formal support networks.

\section{Sample}

Participants for this study were selected purposively based on their specific experiences and their perceived ability to provide the most relevant information to meet the aims of the study (Denscombe 2003, 15). A three-tier approach was taken to sampling. First, information on prospective participants was accessed from monthly statistical returns to produce a list of deceased service users who had been in receipt of social work services from the designated Health and Social Services Trust. Second, dates of birth of the deceased were accessed to ensure all deceased service users were within the age range 35-65 years. This age stipulation was to target middle-aged service users rather than older people. Third, the deaths had to have occurred within the previous 13-23 months. This time period was chosen for ethical reasons in line with Pardoe (1989), who asserts that contact at that time should reduce the likelihood of distress, as individuals have passed important milestones such as anniversaries, birthdays and Christmas. A primary sample group of 57 service users was identified.

The following criteria were applied to the primary group of 57 participants and the number of exclusions produced is noted in parentheses:

- All deaths must have been cancer related. This was due to the nature of the primary researcher's expertise and to ensure commonality of cause of death. (Death not cancer related, $n=8$.)

- All participants must have been a partner or spouse of the deceased patient. This promoted consistency with relationship and ensured openness to unmarried and same-sex partners. (No partner at time of death, $n=25$.) 
- The spouse had not been legally separated or divorced at the time of bereavement. This prevented unnecessary complications with attachment or separation issues. (Separated or divorced, $n=3$.)

- There was no known diagnosis of mental illness. This protected vulnerable service users. (Diagnosed with mental illness, $n=2$.)

- All participants must have been resident within the designated area at the time of death. This ensured access to agency records. (Non-resident in Trust, $n=1$.)

- Participants were not in receipt of social work services from the primary researcher. This avoided bias and maintained rigour. (Received social work services from researcher, $n=4$.)

Fourteen individuals were approached to participate in the study. However, two people declined without explanation, one did not respond, and an anniversary coincided for one. This resulted in a final sample group of 10 (five male and five female) who were willing to participate and fulfilled the sampling criteria.

\section{Research Instrument}

Although the semi-structured interview was based on a self-designed questionnaire, content was closely linked to findings of previous work in this area (Worden 1991; Addington-Hall and McCarthy 1995; Daggett 2002; Scannell-Desch 2003). The interview questionnaire consisted of 14 questions. Depth of exploration was gauged during the interview and further open or closed questioning was applied as necessary. Seven key areas were covered in all cases:

1. Interview checklist (e.g. consent form signed and returned, consent to tape record interview, date, place and length of interview).

2. Demographic details of participants (e.g. age, gender, relationship to deceased and family composition).

3. The event (e.g. the illness and death of their partner, demographic details of deceased partners including age, gender, cause and place of death, communication regarding illness, treatment or concerns about dying and issues resulting from communication or non-communication).

4. The impact of bereavement (e.g. initial impact, main concerns postbereavement, impact on health, finances, employment, family or children, socially, effect on mental health, emotionally or psychologically and spiritually).

5. Experiences of informal support (e.g. who was around for support and how did they help).

6. Experiences of voluntary and statutory sector support services (e.g. what help was received, how it was accessed, what type of support was received and the frequency and duration of contact). 
7. Evaluation of services (e.g. barriers or problems in accessing support, to describe what support had been most useful or least useful since bereavement and to identify any gaps in bereavement support).

On gaining ethical approval from the University Research Ethical Committee, the research instrument was piloted using one adult male who lived outside the designated area but who met the remaining criteria. This led to minor refinement and amendments. The importance of allowing partners to tell their story from the point of diagnosis was recognised and consideration was given to ensure partners reflected on the impact of the research interview experience. An eighth section was subsequently added to the interview schedule for debriefing about interview impact (Emanuel et al. 2004).

\section{Data Collection}

Correct ethical procedures were followed throughout in accordance with the University of Ulster Research Ethical Committee. Moreover, guidelines for conducting bereavement research (Parkes 1995) were followed in recognition of the very sensitive and potentially distressing nature of the subject area. For this reason, face-to-face interviews were chosen over a distance method of data collection in order that the sensitive nature of the research topic might be appropriately explored consistently and to allow people to tell their own story.

Methodological activity followed the sequence now described. Potential participants were initially contacted for consent by the social worker originally assigned to the deceased patient and who had conducted post-bereavement follow-up support. A written explanation of the project citing the purpose and method of the research, the credentials of the researcher, precautions taken to protect anonymity and explanations of the right to withdraw at any time without consequence was provided. This was followed up with an explanatory visit to obtain written consent for participation and tape recording. Interviews were undertaken over a five-week period in 2004. All participants agreed to the interview being conducted in their home to facilitate privacy, emotional comfort and ease of participation. Duration of interviews ranged from 40-65 minutes. All interviews were facilitated by the same researcher to maintain consistency. No participants withdrew from the study.

\section{Data Analysis}

Eight out of ten participants gave consent for the interview to be tape recorded. Taped interviews were transcribed verbatim by the principal researcher to protect the anonymity of participants. In the remaining two cases, extensive case notes were made during interviews and further notes were made from memory immediately following the interview to help qualify and contextualise notes. 
Each transcript produced between six and 14 pages of data. A primary analysis of each transcript was carried out by the principal researcher (AA) by repeatedly reading, summarising and grouping responses using a thematic content analysis approach (Ritchie and Lewis 2005). Transcripts were studied using a manual method to draw out the main points and categorise these under emerging headings or themes. A manual method was used due to sample size and nature of interviews. A duplicate sample (30\%) of transcripts was analysed independently by the project supervisor (RM) and another research reviewer (KD) to moderate interpretation and to augment reliability. Where differences in interpretation occurred, a final decision was made by agreed consensus.

Preliminary coding was carried out by the principal researcher using a devised framework. After completion, the principal researcher, the supervisor and the other research reviewer re-read transcripts and reviewed codes to ensure that emerging themes clearly originated from the data. Additional themes were identified, other points were re-categorised and relevant quotes that encapsulated the meaning of emerging themes were identified. Data were merged into four categories:

1. The cancer journey

2. The impact of bereavement

3. The process of adjustment and change

4. The experience of support services

\section{Findings}

\section{Sample}

All participants were from an urban area of Northern Ireland served by one Health and Social Services Trust. Demographic details of participants interviewed for the study are outlined in Table 1 . The age of bereaved partners ranged from 39 to 64 years (males) and 46 to 61 years (females), with the mean age of their deceased partners 56 years (males) and 48 years (females). All participants were white (100\%) and the majority described their nationality as British (80\%) and the remainder as Irish (20\%).

Four partners were dependent on statutory benefits due to sickness or retirement and six were employed either full or part time. Eight couples were married, two cohabitated long-term with their respective partners and all partners had two or more children, with the exception of one same-sex couple. Demographic details of deceased patients are outlined in Table 2. The age of deceased partners ranged from 36 to 63 years of age, with the mean age of deceased patients 56 years (male) and 48 years (female). All were described as white (100\%) and the majority were described as British (80\%). The length of illness ranged from 1 to 84 months (mean 19 months), or 10 months on average if those who were in remission between primary and secondary diagnosis were omitted. In relation to place of death three individuals died in a hospice, three in hospital, three at home and one in a nursing home (in three cases, partners were cared for at home until being admitted to hospital or hospice days or weeks before death). 
Table 1. Bereaved partners.

\begin{tabular}{lc}
\hline Details of bereaved participants & Participants $(n=10)$ \\
\hline Gender of participant & 5 \\
Male & 5 \\
Female & \\
Age of participant & 1 \\
$30-39$ & 2 \\
$40-49$ & 4 \\
$50-59$ & 3 \\
$60-65$ & \\
Ethnicity & 10 \\
$\quad$ White & \\
Nationality & 8 \\
British & 2 \\
Irish & \\
Employment status & \\
Employed full or part time & 6 \\
Incapacity benefit & 2 \\
Retired & 2 \\
Relationship to deceased & \\
Spouse & \\
Partner & 8 \\
\hline
\end{tabular}

\section{Thematic Content Analysis}

Four core themes emerged from the thematic content analysis procedure (Ritchie and Lewis 2005): the cancer journey; the impact of bereavement; the process of adjustment and change; and the experience of support services. These will now be discussed.

\section{The Cancer Journey}

Participants described how this journey commenced at diagnosis with the shock of bad news, which was always broken by a doctor. However, experiences were mixed with half of participants reporting a sympathetic communication and the other half describing the interview manner as blunt and insensitive. Partners also coped with making difficult treatment decisions and hearing news of secondary cancer or treatment withdrawal which had a shattering and overwhelming impact:

She was diagnosed ... and it was pretty traumatic ... we went home in a state of shock. It did feel pretty much that we had been told this news and then dumped out on our own ... like you were just being put adrift on your own. I felt pretty much alone at that time and I didn't really feel we got an awful lot of support then ... I think the second diagnosis was harder ... the prognosis was quite good although they had been optimistic. 
Table 2. Deceased partners.

\begin{tabular}{lc}
\hline Details of deceased partners & Participants $(\mathrm{n}=10)$ \\
\hline Gender of deceased & 6 \\
Male & 4 \\
Female & \\
Age of deceased & 1 \\
$30-39$ & 2 \\
$40-49$ & 4 \\
$50-59$ & 3 \\
$60-65$ & \\
Ethnicity & 10 \\
White & \\
Nationality & 8 \\
British & 2 \\
Irish & \\
Length of illness (months) & 3 \\
1-6 months & 1 \\
$7-12$ months & 4 \\
13-18 months & \\
19-24 months & 0 \\
Over 24 months & 2 \\
Place of death & \\
Home & 3 \\
Hospice & 3 \\
Hospital & 3 \\
Residential/nursing home & 1 \\
\hline
\end{tabular}

This participant's statement reflects his feelings of isolation and abandonment. Other participants indicated that their anticipatory grief commenced either at the point of diagnosis, or on receiving news of a secondary disease or at the withdrawal of treatment. Partners described their anticipation of widowhood and life as a lone parent when they were fully aware that their partner was going to die and reported a need to openly communicate with their dying partner how they would cope after his/her death. However, opportunities to do so were often limited due to communication problems between partners caused by the physical impact of the disease, avoidance due to fear of dying, avoidance by the carer due to fear of the impending death and the contemporary social taboo of discussing death. Consequently, partners who had previously enjoyed open communication felt disappointment, frustration and anger:

We had been married 30 years and talked about everything and we came to a very important part of her life, her death, and couldn't talk about it... I was disappointed.

For three participants, communication difficulties were resolved pre-bereavement by intervention from professional staff, but in three other cases communication difficulties persisted right up to death. 
Regardless of the length of the cancer journey and their apparent preparedness for the impending death, all partners were overwhelmed by shock at the finality of death. A range of emotions were reported: Anger, ranging greatly in intensity and perceived cause 'I was very angry ... at the whole world' and survivor guilt at living on or having not known or done enough about their partner's cancer and its treatment:

The worst feeling for me ... was guilt at living on, which would have been much sharper without the children ... there was a lot of guilt about the cancer and it developing ... I wish I had known more.

\section{Impact of Bereavement}

\section{Mentally}

Despite the fact that a diagnosis of a mental illness was an exclusion criterion for this study, data indicated that mental health problems were common in the sample $(n=7)$ following bereavement and included cancer phobias, overwhelming feelings of hopelessness, depression and panic attacks. Strikingly, findings revealed that four participants' feelings of hopelessness were sufficiently overwhelming for them to contemplate suicide. One male partner stated:

I was going to commit suicide. I thought about it a lot and actually planned out how to do it ... I was in turmoil.

Seven partners were treated for depression with prescribed medication after loss of hope, energy, motivation and interest in the future. One partner said:

I was depressed and my mental health was not good. I got Prozac ... I don't have any ambition in me. I'll just carry on until it's my turn to die.

None of the participants indicated an awareness of a bereavement risk assessment process being undertaken by a professional, but two service users independently recommended the need to assess the suicidal risk associated with bereavement. One participant stated it was better to 'detect suicidal thoughts rather than wait until someone kills themselves'. Participant accounts indicated no knowledge of bereavement vulnerability or risk assessments being completed. Participants felt it was up to them to identify their own vulnerability and to actively seek help for their mental health problems resulting from bereavement. Secondary evidence indicates that bereavement risk assessments were undertaken in the voluntary sector hospice settings where all service users were offered bereavement support, whereas the community social work team did not complete assessments to identify those at high risk and post bereavement followup was ad hoc depending on case load priorities. 


\section{Financially}

Findings indicated that in terms of financial status and social backgrounds, the majority $(n=7)$ of participants were on a fixed low income due to ill health or part-time employment. Although five participants indicated they had no concerns about money, they did refer to 'making do with very little'; three people returned to work due to loss of income and apprehension about coping; and one participant made explicit reference to financial pressure: 'Money is a big thing and it still is.' Finally, in one case life insurance resulted in the surviving partner being better off post-bereavement.

\section{Socially}

All participants reported feeling lonely and mourned the loss of a companion to share the day's events with. Social isolation was more evident when participants experienced what they felt was a lack of insight by family and friends as to the depth of their loss when they felt society in general was impatient of their grieving and their need to express it. In addition, four female participants referred to what was perceived as the 'couples world' we live in or feeling like the 'third person' or 'odd one out in social circles'. Some also had difficulty coping with changes to existing social networks and friendships due to their belief that other wives perceived them as a 'threat'. Although male participants acknowledged their loneliness, there was evidence that they were motivated to search for new relationships or friendships and to begin to re-integrate quicker than the female bereaved.

\section{Spiritually}

Spiritual beliefs were a dominant theme from the interviews. Participants reported that their spiritual beliefs were challenged, relinquished or strengthened. Four participants who had close links with their local church benefited from high levels of support: 'Our minister ... called a couple of times a week for the first year ....' They found their Christian faith a comfort during bereavement, whereas other participants described a loss of faith, expressed anger at God for 'unanswered prayers' and one participant described his spiritual life as a 'casualty' of his grief experience.

\section{Adjustment and Change}

Participants reported a numbness throughout the first year of bereavement which prevented them adjusting or feeling the pain of their loss. Issues of adjustment included lone parenthood, living alone and questioning life values. Family experiences across the sample varied, as participants were at different stages of 
parenthood. Fears were expressed by one parent about his situation: 'I had to sort child care because I didn't want to lose my career as well as losing [my wife].' In some instances, childcare responsibilities gave a purpose to life and a motivation to carry on. Participants reported difficulties adjusting to living alone, losing direction in life and thoughts about looking for a new partner. One participant talked about having to 'reinvent' himself after realising that he had changed forever and could not spend life 'looking back'. Others recognised their need to live in the present: 'I don't really look too far ahead, just take things day by day, plodding along ... just have to cope with what life throws at you.'

\section{Experience of Support Services}

Informal networks of family, friends and neighbours were the most cited source of support $(n=9)$. When the provision of voluntary and statutory services was analysed it was apparent that GPs were in contact with the majority of participants $(n=8)$; social workers were next most important $(n=7)$, followed by voluntary sector bereavement care $(n=3)$ and nurses $(n=2)$. A more complete overview of findings follows.

\section{Informal support}

Participants in this study emphasised strong family support, although limitations were recognised due to relatives' own need to grieve or their limited insight into the depth of loss. One female participant stated:

I know that if I started to talk about my loneliness my mother would look at me. My sister is single, she's had no experience of married life and has no children and I feel she wouldn't understand.

Work colleagues and neighbours also provided a listening ear. One participant explained the benefits of having access to bereavement literature:

I was reading about bereavement in this book, it talks about getting to a stage where I put it behind me. Books do help as they answer some questions.

Findings revealed that despite their limitations informal networks of family and friends were a valuable source of support for the bereaved.

\section{Formal support (voluntary sector)}

The approach adopted in local hospices is proactive where social workers meet with patients and families to conduct a psychosocial assessment as part of the 
multidisciplinary team response and post-bereavement follow-up is offered to all caregivers. Although participants whose partners had died in the hospice were grateful for such offers of bereavement services, the majority declined it and expressed a stoical approach or were motivated by a lack of self-awareness of their needs, a limited understanding of counselling services or a perceived stigma in accepting professional bereavement support. Moreover, participants also expressed reluctance to engage in bereavement groups offered. One described his thoughts:

I didn't like the groups. I found it really hard, it was too depressing ... everybody had a tale to tell and every time somebody talked it was like you were telling yours and you can only take that so often.

In contrast, another participant, who during the interview reported mental health problems, felt discriminated against because he had not been offered bereavement follow-up support as his partner had transferred from hospice care to die in a nursing home. One participant who had attended individual counselling at a voluntary bereavement organisation reported an uncertainty about its benefits:

I don't know if it helped me or not. I would have gone and cried my eyes out. I went there six times. I never bothered going back. I found it too difficult.

\section{Formal support (statutory services)}

For others, whose partners had died in the community $(n=3)$ or in hospital $(n=3)$, bereavement assessments were not completed and bereavement support was not consistently offered. Participants attended their general practitioner (GP) in the first instance. Prescribed medication, medical certificates and a listening ear were beneficial although one participant emphasised the short time allocated for a GP consultation and the lack of continuity. For one service user her GP was a key person who took a holistic approach to her needs:

She's very good and she asked me how I was doing, how I was financially, she advised me and gave me tablets.

If deemed in need of intervention, GPs referred participants to a voluntary sector bereavement service or to a community psychiatric nurse. There was a mixed response from participants about the nature and quality of social work support. Feedback from those who had received post-bereavement support from social work staff was unanimously positive. Findings indicated that social workers were reliable, available and that continuity of worker pre- and post-bereavement was valued. A number of participants raised the need to 
promote counselling and bereavement support services as part of the social work role:

People think they can do it on their own, I did ... I should have got counselling. There should be more done for people left behind. There are counselling services, but you have to ask ... I hadn't the strength to do that ... the social worker did call but I suppose he thought I was coping.

Post-bereavement social work support was not offered consistently to all participants possibly because of competing workload demands; poor knowledge of bereavement risk assessment factors; inappropriate timing of intervention; or a general reluctance of participants to engage with agencies. Participants reported that informal and formal support services were not offered in the second year of bereavement, which may have heightened the social isolation and stigma associated with grief.

\section{Discussion and Conclusion}

Although this study was small in scale and undertaken in a single designated Health and Social Services Trust in Northern Ireland, its findings provide evidence of the experiences of middle-aged partners bereaved through cancer. On the basis of these findings a framework for good palliative care social work practice is proposed (Figure 1).

Our results highlight key skills, knowledge and values that should be adopted by healthcare professionals involved in the provision of care to patients and families. Participants stressed the importance of continuity, flexibility and accessibility of service delivery which clearly offers challenges for palliative care professionals. Findings agreed with previous reports that the cancer journey and anticipatory grief starts at the point of diagnosis for both patient and family (Kubler-Ross 1969; Bass and Bowman 1990). Findings illustrated that regardless of the cancer journey duration, participants experienced intense emotions following the death of their partner which staff must recognise to help prioritise families at times of increased distress.

Findings raised issues around communication either between patient and bereaved partner or with the health professional as third party. The 'Breaking Bad News Guidelines' (National Council for Hospice and Specialist Palliative Care Services 2003) provide guidance for healthcare professionals and recommend the presence of a supportive person. Reports of insensitive communication by doctors enhanced the bad news episode to leave families feeling traumatised and isolated; these feelings often remained with relatives into bereavement, a finding in keeping with other literature (Fallowfield 1993). The shock and isolation expressed by participants illustrated the need for continuous professional support and not to assume that disease recurrence is less devastating news than the initial diagnosis. Another reported communication issue was on preferred place of care (Storey et al. 2003). Here participants emphasised that 


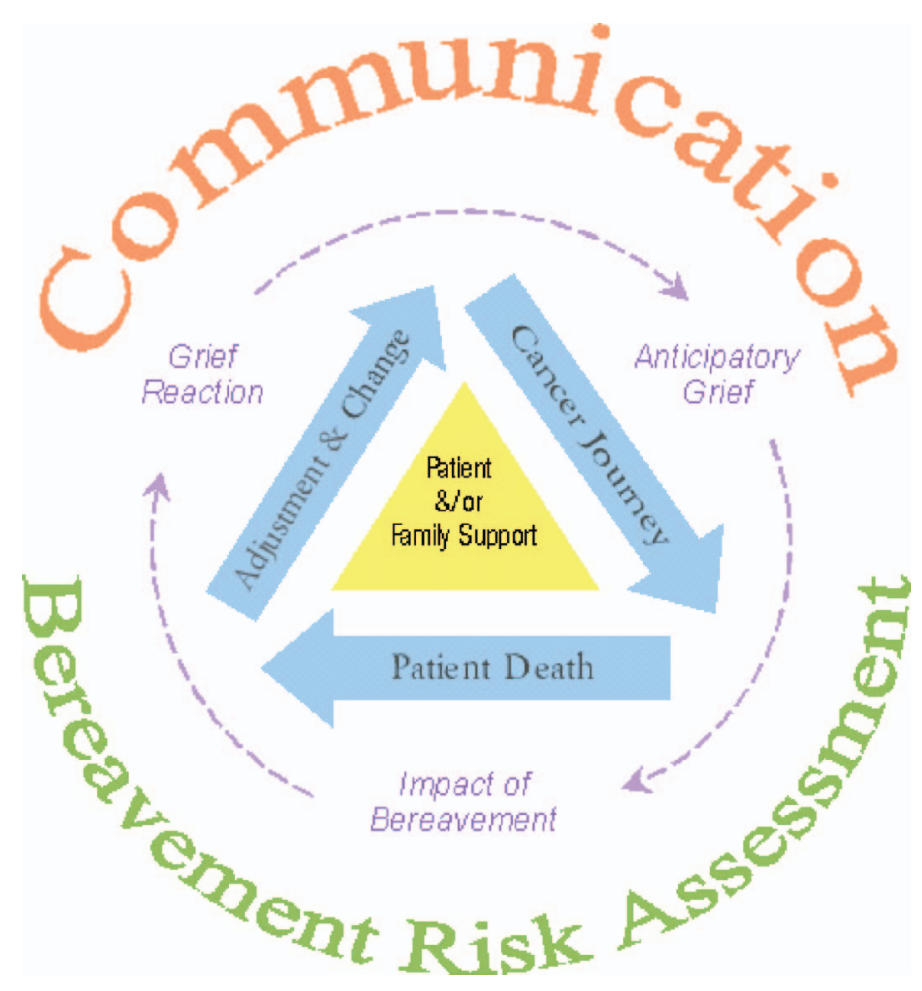

Figure 1. Overview of framework of good practice for health care professionals providing pre- and post-bereavement support.

where service users were transferred to hospice or hospital in the last weeks or days of life, their partners felt that decision-making was resource-led rather than based on quality-of-life assessments. Preferred place of care should be sensitively discussed with service users and families and reviewed regularly in line with changing needs.

Palliative care professionals should be adequately skilled to address communication barriers between service users and family/caregivers and offer a safe forum for exploring issues to complete unfinished business. Findings revealed that communication was not always facilitated, which resulted in poor bereavement outcomes, unresolved emotions and even suicidal ideation. This privileged access to families should not be wasted as intervention is known to reduce such outcomes (Kelly et al. 1999; Barry et al. 2002; CFAH 2003). This aspect of practice in the palliative care arena is now influenced by the Liverpool Care Pathway guidelines (Jack et al. 2003).

The experience of social isolation is integral to the bereavement process (Worden 1991; Daggett 2002) and highlights the importance of informal and formal caregivers understanding the need to respect the individuality and complexity of the grieving process. After one year, the possibility of 'relocating the deceased' (Worden 1991) was still a very raw and emotive step for the majority of participants and few had fully accepted the death of their partner. 
Adjusting to loss was a core problem for all participants. Given the continuum of emotional reactions it is clear that professional risk assessment post-bereavement is vital.

In keeping with other work (Aranda and Milne 2000) our findings recommend that social work staff should use structured documentation which promotes service user involvement to ensure that bereavement assessments and care plans are based on accurate information. In line with this point, a number of sources (Walshe 1997; Lev and McCorkle 1998; BrintzenhofeSzoc and Smith 1999; Aranda and Milne 2000; Walshe-Burke 2000; NICE 2004) advise that service users who are assessed as being at greatest risk of poor bereavement outcome should be proactively targeted to avoid the rather uncertain route of self-referral. NICE guidance (2004) outlines a framework for the provision of bereavement services. Evidence suggests, however, that services which do not target resources to those most at risk of poor bereavement outcome are counter-productive and do not promote resilience (Walshe 1997; Parkes 2006). Findings in this study uncovered that participants had no knowledge of bereavement risk assessments being completed and felt that their poor mental health status had been left undetected. Moreover, although universal bereavement support was offered, participants expressed reluctance to accept intervention. Reasons included the timing of invitations, limited choice regarding service providers or types of service, or participants not recognising their own needs. Bereaved partners who were not offered support felt discriminated against and most participants tended to seek intervention personally from their GP or specialist counselling services.

In relation to choice of support, informal support networks were found to be the most valued source of help; this is in keeping with other reports (Brazil et al. 2003). However, in the second year of bereavement, when intensity of the grieving process was underestimated or overlooked, emphasis shifted towards formal support. GPs and social workers were the preferred professionals because they were already known to the family. Notwithstanding this, Beresford et al. $(2007,206)$ state that social work is beset by internal uncertainty and external misunderstanding due to a widespread lack of knowledge about what social workers do and that palliative care social work is not universally available. Social workers must raise their profile within palliative care, access training in bereavement assessment, utilise evidence-based assessment methods, offer bereavement services for families in partnership with other agencies and provide accessible information on grief reactions and service delivery (Parkes 1993; NICE 2004) to promote empowerment, respect individuality and offer choice and flexibility.

\section{References}

Addington-Hall, J., and M. McCarthy. 1995. Regional study of care for the dying: Methods and sample characteristics. Palliative Medicine 9(1): 27-35.

Addington-Hall, J. M. 2007. Introduction. In Research methods in palliative care, edited by J. M. Addington-Hall, E. Bruera, I. J. Higginson, and S. Payne. Oxford: Oxford University Press. 
Aranda, S., and D. Milne. 2000. Guidelines for the assessment of complicated bereavement risk in family members of people receiving palliative care. Melbourne: Centre for Palliative Care.

Arbuckle, N., and B. de Vries. 1995. The long-term effects of later life spousal and parental bereavement on personal functioning. The Gerontologist 35(5): 637-47.

Archer, J. 1999. The nature of grief: The evolution and psychology of reactions to loss. London: Routledge.

Barry, L. C., S. V. Kasl, and H. G. Prigerson. 2002. Psychiatric disorders among bereaved persons: The role of the perceived circumstances of death and preparedness for death. American Journal of Geriatric Psychiatry 10(4): 447-57.

Bass, D. M., and K. Bowman. 1990. The transition from caregiving to bereavement: The relationship of care-related strain and adjustment to death. The Gerontologist 30(1): 35-42.

Beaver, K., K. Luker, and S. Woods. 1999. The views of terminally ill people and lay carers on primary care services. International Journal of Palliative Nursing 5(6): 266-74.

Benight, C., J. Flores, and T. Tashiro. 2001. Bereavement coping self-efficacy in cancer widows. Death Studies 25(2): 97-125.

Beresford, P., L. Adshead, and S. Croft. 2007. Palliative care, social work, and service users: Making life possible. London: Jessica Kingsley.

Birtwistle, J. 2004. Bereavement support: the perspective of community nurses. In Palliative care nursing: Principles and evidence for practice, edited by S. Payne, J. Seymour, and C. Ingleton. Buckingham: Open University Press.

Bowlby, J. 1969. Attachment and loss. Vol 1: Attachment. New York: Basic Books.

Brazil, K., M. Bedard, and K. Willison. 2003. Bereavement adjustment and support among caregivers. Journal of Mental Health and Aging 9(3): 193-204.

BrintzenhofeSzoc, K. M., and E. D. Smith. 1999. Screening to predict complicated grief in spouses of cancer patients. Cancer Practice 7(5): 223-39.

Centre for the Advancement of Health. 2003. Report on bereavement and grief research. Grief Research: Gaps, needs and actions report. Washington, DC [accessed 22 February 2007]. Available at www.cfah.org

Chrystal-Frances, E. 2003. Palliative care: A discussion of management and ethical issues. Nursing Forum 38(2): 25.

Daggett, L. M. 2002. Living with loss: middle-aged men face spousal bereavement. Qualitative Health Research 12(5): 625-39.

Denscombe, M. 2003. The good research guide for small-scale social research projects, 2nd edn. Philadelphia: Open University Press.

Eaton, L. 1998. Good grief? Community Care 27 August-2 September: 24-26.

Emanuel, E. J., D. L., Fairclough, P., Wolfe, and L. L. Emanuel. 2004. Talking with terminally ill patients and their caregivers about death, dying, and bereavement: Is it stressful? Is it helpful? Archives of Internal Medicine 164(18): 1999-2004. [accessed 10 July 2007]. Available at www.archinternmed.com

Exley, C., and F. Tyrer. 2005. Bereaved carers' views of a hospice at home service. International Journal of Palliative Nursing 11(5): 242-46.

Fallowfield, L. 1993. Giving sad and bad news. Lancet 341(8843): 476-8.

Firth, P., G. Luff, and D. Oliviere. 2005. Loss, change and bereavement in palliative care. Buckingham: Open University Press.

Freud, S. 1917. Mourning and melancholia. The Standard Edition of the Complete Psychological Works of Sigmund Freud, under general editorship of James Strachey, in collaboration with Anna Freud, assisted by Alix Strachey and Alan Tyson. 1953. London: Hogarth Press 14: 239-58.

Harris, T., and T. Kendrick. 1998. Bereavement care in general practice: a survey in South Thames Health Region. British Journal of General Practice 48(43): 1560-64. 
Jack, B. A., M. Gambles, D. Murphy, and J. E. Ellershaw. 2003. Nurses' perceptions of the Liverpool Care Pathway for the dying patient in the acute hospital setting. International Journal of Palliative Nursing 9(9): 375-81.

Kelly, B., P. Edwards, R. Synott, C. Neil, R. Baillie, and D. Battistutta. 1999. Predictors of bereavement outcome for family carers of cancer patients. Psycho-oncology 8(3): 23749.

Kissane, D., S. Bloch, and D. McKenzie. 1997. Family coping and bereavement outcome. Palliative Medicine 11(3): 191-201.

Kubler-Ross, E. 1969. On death and dying. New York: Macmillan.

Lev, E. L., and R. McCorkle. 1998. Loss, grief, and bereavement in family members of cancer patients. Seminars in Oncology Nursing 14(2): 145-51.

Lindemann, E. 1944. The symptomatology and management of acute grief. American Journal of Psychiatry 101(2): 141-48.

Lloyd-Williams, M. 1995. Bereavement referrals to a psychiatric service: an audit. European Journal of Cancer Care 4(1): 17-19.

Machin, L. 2001. Exploring a framework for understanding the range of response to loss; a study of clients receiving bereavement counselling. Unpublished PhD thesis, Keele University, UK.

Machin, L., and B. Spall. 2004. Mapping grief: A study in practice using a quantitative and qualitative approach to exploring and addressing the range of responses to loss. Counselling and Psychotherapy Research 14(1): 9-17.

Main, J. 2000. Improving management of bereavement in general practice based on a survey of recently bereaved subjects in a single general practice. British Journal of General Practice 50(460): 863-66.

National Council for Hospice and Specialist Palliative Care Services. 2003. Breaking bad news ... regional guidelines. Belfast: Department of Health, Social Services and Public Safety.

National Institute for Clinical Excellence (NICE). 2004. Guidance on cancer services: Improving supportive and palliative care for adults with cancer. London: NICE.

Northern Ireland Cancer Registry. 2005. [Accessed 3 August 2007]. Available at www.qub.ac.uk/researchcentres/nicr

Osterweiss, M., F. Solomon, and M. Green. 1984. Bereavement: Reactions, consequences and care. Washington, DC: National Academy Press.

Pardoe, J. 1989. The role of the social worker. In Caring for the dying patient and the family, 2nd edn, edited by J. Robbins. London: Harper \& Row Publishers.

Parkes, C. M. 1986. Bereavement: Studies of grief in adult life, 2nd edn. Harmondsworth: Pelican.

. 1993. Bereavement. In Oxford textbook of palliative medicine, edited by D. Doyle, G.W. Hanks, and N. MacDonald. Oxford: Oxford University Press.

- 1995. Guidelines for conducting ethical bereavement research. Death Studies 19(2): $171-81$.

- 2006. Love and loss: the roots of grief and its complications. London: Routledge.

Parkes, C. M., and R. Weiss 1983. Recovery from bereavement. New York: Basic Books.

Purandare, L. 1997. Attitudes to cancer may create a barrier to communication between the patient and caregiver. European Journal of Cancer Care 6(2): 92-99.

Reid, D., D. Field, S. Payne, and M. Relf. 2006. Adult bereavement in five English hospices: Participants, organisations and pre-bereavement support. International Journal of Palliative Nursing 12(7): 320-27.

Ringdal, G. I., M. S. Jordhoy, K. Ringdal, and S. Kaasa. 2001. The first year of grief and bereavement in close family members to individuals who have died of cancer. Palliative Medicine 15(2): 91-106. 
Ritchie, J., and J. Lewis. 2005. Qualitative research practice: A guide for social science students and researchers. London: Sage Publications.

Scannell-Desch, E. 2003. Women's adjustment to widowhood: Theory, research and interventions. Journal of Psychosocial Nursing and Mental Health Services 41(5): 28-36.

Storey, L., C. Pemberton, A. Howard, and L. O'Donnell. 2003. Place of death: Hobson's choice or patient choice? Cancer Nursing Practice 2(4): 33-38.

Stroebe, M. S., and H. A. W. Schut. 1999. The dual process model of coping with bereavement: rationale and description. Death Studies 23(3): 197-224.

Stroebe, M. S., S. Folkman, R. O. Hansson, and H. Schut. 2006. The prediction of bereavement outcome: Development of an integrative risk factor framework. Social Science and Medicine 63(9): 2440-51.

Stroebe, W., and H. Schut. 2001. Risk factors in bereavement outcome: A methodological and empirical review. In Handbook of bereavement research: Consequences, coping and care, edited by M. S. Stroebe, R. O. Hansson, W. Stroebe, and H. Schut. Washington, DC: American Psychological Association.

Valentine, C. 2006. Academic constructions of bereavement. Mortality 11(1): 57-78.

Walshe, C. 1997. Whom to help? An exploration of the assessment of grief. International Journal of Palliative Nursing 3(3): 132-37.

Walshe-Burke, K. 2000. Matching bereavement service to level of need. Hospice Journal 15(1):77-86.

Worden, J. W. 1991. Grief counselling and grief therapy: A handbook for the mental health practitioner, 2nd edn. London: Tavistock/Routledge.

Audrey Agnew, BA PG Dip SW PQSW MSc AASW, is a senior social worker in Marie Curie Hospice Belfast and a part-time tutor at Queen's University Belfast. She has worked as a researcher (social work) for Marie Curie Palliative Care Research Unit and as a community social worker specialising in palliative care with adults and families. Correspondence to Audrey Agnew, Marie Curie Hospice, 1a Kensington Road, Belfast, BT5 6NF, Northern Ireland. email: audrey.agnew@mariecurie. org.uk; Roger Manktelow, BA MSc PhD, is a lecturer in social work at the School of Sociology and Applied Social Studies, University of Ulster at Magee, Derry, Northern Ireland. He has researched and published on aspects of health and illness including help-seeking behaviour, the mental ill-health effects of the Troubles in Northern Ireland and the family impact and recovery of individuals suffering from enduring mental illness. email: r.manktelow@ulster.ac.uk; Kevin Donaghy, BSC PGCE PGCHET LETTOL PhD, is a lecturer in Cancer/Palliative Care, Marie Curie Hospice Belfast. He is affiliated with the Wolfson Institute of Health Sciences and Thames Valley University. email: Kevin.donaghy@mariecurie.org.uk 